\title{
A Smart Community Energy Management Scheme Considering User Dominated Demand Side Response and P2P Trading
}

\author{
Suyang Zhou ${ }^{1}$, Fenghua Zou ${ }^{1}$, Zhi Wu ${ }^{1}$, Wei Gu ${ }^{1 *}$, Qiteng Hong ${ }^{2}$, Campbell Booth ${ }^{2}$ \\ ${ }^{1}$ School of Electrical Engineering, Southeast University, 2 Sipailou Xuanwu Qu, Nanjing, China \\ ${ }^{2}$ Department of Electronics and Electrical Engineering, University of Strathclyde, Glasgow G1 1XW, Scotland, \\ U.K \\ *wgu@seu.edu.cn
}

This paper proposed a Peer-to-Peer (P2P) local community energy pool and a User Dominated Demand Side Response (UDDSR) that can help energy sharing and reduce energy bills of smart community. The proposed UDDSR allows energy users within the community to submit flexible Demand Response (DR) bids to Community Energy Management Scheme (EMS) with flexible start time, stop time and response durations with regard to users' comfort zones for electric heating systems, electric vehicles and other home appliances, which gives maximum freedom to the DR participants. The scheduling of the DR bids, originally a multi-objective optimization problem (maximize the total flexible demand and the flexible demand in every interval during the whole DR duration), is transferred to a single objective optimization problem (maximize the total demand with penalty for demand imbalance during the whole DR duration) that can significantly decrease the computational complexity. Furthermore, to facilitate efficient energy usage among neighbourhoods, a local energy pool is also proposed to enable the energy trading among users aiming to facilitate the usage of surplus energy within the community. The electricity price of energy pool is determined by the real-time demand/supply ratio, and upper/lower limit for the price is configured to ensure the profitability for all the participants within the pool. To evaluate the performance of proposed UDDSR and local energy pool, comprehensive numerical analysis is conducted. It is found that the energy pool participants without PV can get at least $6.16 \%$ savings on electricity bill (when PV penetration level equals to $20 \%$ ). The energy pool participants with PV can get much better return (at least $\mathbf{1 3 . 4 \%}$ profit increase) on the PV generation compared to the conventional Feed-in-Tariff. If energy users join the UDDSR scheme, the participants can get further return, and the proposed UDDSR can provide a constant load reduction/increase during the every time interval of the whole DR event. If Battery Energy Storage System (BESS) is included in the DR operation, the usage efficiency of customers' flexible loads can achieve more than $85 \%$.

\section{NOMENCLATURE}

$a(t) \quad$ Time-dependent non-negative parameters.

$\mathrm{b}(\mathrm{t}) \quad$ Time-dependent non-negative parameters.

$b_{i}(t) \quad$ A binary value denoting the scheduling of the appliances (appliance $=$ OFF if $b_{i}(t)=1$ and appliance $=\mathrm{ON}$ if $\left.\mathrm{b}_{\mathrm{i}}(\mathrm{t})=0\right)$.

$\mathrm{c}(\mathrm{t})$ Time-dependent non-negative parameters.

$\mathrm{d}(\mathrm{t})$ the real-time TOU price.

$e_{i}(t) \quad$ The energy feed into/purchase from the grid of participant $\mathrm{i}$.

$\mathrm{e}_{\mathrm{i}}^{\mathrm{B}}(\mathrm{t}) \quad$ The energy bought from energy pool.

$p_{m}(t) \quad$ The aggregated amount of energy that $m$ users are selling to the pool.

$p_{(n-m)}(t)$ The aggregated demand amount of the left $(n-m)$ users that are requesting energy from the pool.

$\mathrm{p}^{\mathrm{F}} \quad$ The Feed-in-Tariff (FIT).

$\mathrm{t}$ The $\mathrm{t}$-th time slot.

$\gamma_{n}(t) \quad$ The ratio of the aggregated supplier and demand at time $t$ in the energy pool.

$\delta \quad$ The penalty factor refers to the impact of balancing the allocated power at the time interval for the objective function.

$\eta^{c} \quad$ The charging efficiency.

$\eta^{\mathrm{d}} \quad$ The discharging efficiency.

$\chi \quad$ The unit price of subsidy for normal participants.

$\chi_{\mathrm{B}} \quad$ The unit price of subsidy for BESS.
$\mathrm{C}_{\mathrm{i}}^{\mathrm{U}} \quad$ The credit allocated to participant $\mathrm{i}$.

$\mathrm{C}_{\mathrm{B}}^{\mathrm{U}} \quad$ The credit allocated to BESS.

$C_{i}(t) \quad$ The credit $\left(\mathrm{C}_{\mathrm{i}}(\mathrm{t}) \geq 0\right)$ or bill $\left(\mathrm{C}_{\mathrm{i}}(\mathrm{t})<0\right)$ of participant $\mathrm{i}$ at time $\mathrm{t}$.

$E_{(t)}^{B t} \quad$ The capacity of BESS at time $t$.

$\mathrm{E}^{\mathrm{Bt}} \quad$ The maximum BESS capacity.

$E^{D}(t) \quad$ The sum of scheduled power at time interval $t$ during the DR event.

$E_{L L} \quad$ The lower limit of demand change required by DR scheme

$E_{U L} \quad$ The upper limit of demand change required by DR scheme

$N^{\prime} \quad$ The number of time intervals in one UDDSR event.

$\mathrm{P}_{\mathrm{n}}(\mathrm{t}) \quad$ The aggregated local load profile.

$\mathrm{P}_{\mathrm{t}}^{\mathrm{b}} \quad$ The charging/discharging rate of BESS at time $\mathrm{t}$,

$\mathrm{P}_{\mathrm{c}}^{\mathrm{b}} \quad$ The BESS maximum charging rate,

$\mathrm{P}_{\mathrm{d}}^{\mathrm{b}} \quad$ The BESS maximum discharging rate and

$\mathrm{P}_{\mathrm{i}}(\mathrm{t}) \quad$ The rating power of participant's appliance,

$\mathrm{S}_{\mathrm{t}}^{\mathrm{B}} \quad$ The charging/discharging state of BESS, and

\section{Introduction}

Continuous development of information, communication, automation and control technologies provides a solid foundation for "Smart Grid" implementation [1]. Accommodating increasingly Distributed Generators (DGs), Electric Vehicles (EVs), Heat Pumpers (HPs) on modern 
power grid without significant customer-funded network reinforcement is one of the anticipated benefits of smart grid $[2,3]$. It was anticipated that the HPs would take large share of domestic heating systems and the EVs will hit $60 \%$ in the UK if the $80 \%$ carbon emission cutting target was to be achieved by $2050[4,5]$. The anticipated electrification of transportation and heating will lead to a dramatic increase of peak electric demand which correspondingly raises the operational challenges to network operators. The conventional approach of solving the operational challenges is network reinforcement that requires significant investments and a long lead time. A number of alternative approaches have been proposed to defer the network reinforcement through the smart grid technologies such as Demand Side Response (DSR), Direct Load Control (DLC) and Time of Use (TOU) Tariff. The most common mechanism of the proposed approaches is to shed the loads during peak-time by providing all kinds of subsidies to customers. It is agreed that such mechanism is an essential way to balance the electricity demand, but there are concerns that the customers' perception to DSR or other similar schemes could be passive if the schemes are lack of flexibility and comfortability-concern for customers/participators.

Previous studies carried out on the management of $\mathrm{EV} / \mathrm{PHEV}$ and heating demands have confirmed the active impact on network operation and network reinforcement deferral [1, 6-14]. A distributed center-free demand management system using Karush-Kuhn-Tucker (KKT) conditions for $\mathrm{PHEV} / \mathrm{EV}$ charging management is proposed in [1]. The proposed approach optimized the charging scheduling of the PHEV/EV considering the departure time of EV and global convergence constraint. Compared to the centralized management methodologies proposed in [6] and [7], the distributed management approach has the advantage of laying down the computation burden of network control centre for scheduling the charging of $\mathrm{PHEV} / \mathrm{EV}$. [8] and [9] presented the distributed demand management approaches which are different from the approach of [1]; the two management approaches managed the EV/PHEVs based on the broadcasted DSR signals sent by network operators or aggregators. Such control methodologies can make the distributed EMS respond to the DSR request more actively but extra computation load is required on the network operator and the aggregator side. Similar research has been carried out on managing the electric heating systems (e.g. air source heat pumps) to assist the network operation in [1013]. [10] proposed a demand response system using heat pumps to maintain the transmission-level network voltage stability. It forms the demand response strategy as a multiobjective optimization problem and uses a two-step optimization procedure to solve the problem. This method considers the end-use comforts as the constraints within an automatic resource control strategy realized by strained optimal power flow. [11-13] presented several dynamic DR strategies to reschedule the heat pumps operations with regard to price signals and network constraint signals. However, the willingness of customers to participate in the DR scheme are less considered in the aforementioned DR strategies. [15] highlighted that only about $13 \%$ customers might accept the DLC program based on a total of 1,499 households from one state in Australia. The main barrier to joining the DLC program for the householders is the distrust of energy companies; householders are resistant to shift the control of the appliances to energy companies [15].

Therefore, a UDDSR strategy is proposed in this paper that allows householders to opt-in/out the DR scheme dynamically and submit elastic DR bids for DR events. In comparison with the aforementioned DR strategies, the UDDSR divides one DR event into multiple small DR events with small time slots so that householders can select the timeslot(s) they want to participate based on their availabilities and comfortabilities. The DR bids submitted by householders can have flexible start/stop time and flexible response durations during the whole DR event and customers have the rights to accept/reject the final dispatching notices broadcasted by the UDDSR.

Moreover, to further satisfy the users within the community and enhance the distribution network's reliability, Peer-to-Peer (P2P) trading is considered as an effective supplement for EMS with DR capability, of which the DR scheme can support the network operation during peak-time and $\mathrm{P} 2 \mathrm{P}$ can facilitate the renewable energy usage in all-day operation[16-18]. [17] proposed a community based electricity market so the surplus renewable energy can be traded among neighbourhoods within the market. [19] proposed a decentralized renewable generation management and demand response system focusing on the power distribution network. The proposed receding horizon control for energy trading inspired the bidding strategy presented in our paper. [20] proposed a stock-exchange-model based local electricity trading platform. This platform allows market participants submit, withdraw and adjust their orders in certain time periods (e.g. five minutes before dispatching).

In this paper, a P2P energy trading pool is proposed allowing a flexible trading among the participants. For the proposed trading pool, this paper modelled the dynamic functions of real-time price using the Surplus-to-Demand ratio rather than the aggregated electricity profile used in [17]. This modification simplifies the electricity price model and ensures the electricity price is always lower than the TOU price but higher than the feed-in-tariff so energy users can be effectively motivated to participate into the trading.

The contributions of this paper are summarized as below:

- This paper presents a full picture of a smart community that is capable of UDDSR and P2P trading. The proposed EMS does not control any devices directly. It merely acts as an agent for exchanging the information among users for $\mathrm{P} 2 \mathrm{P}$ trading and between users and DR providers for DR scheme, which gives the users the maximum autonomy.

- $\quad$ This paper proposes the approach for simplifying the UDDSR problem by transferring a multiobjective optimization problem to a single objective Mixed Integer Linear Programming (MILP) problem, which substantially reduces the computational complexity.

- The proposed electricity pricing model for P2P 
trading reduces the price fluctuation in a real-time electricity market by introducing the surplus-todemand ratio to the pricing function, and reduces the bills for consumers, producers and prosumers in the community.

The rest of the paper is organized as follows. Section 3 presents the infrastructure of the proposed EMS, the associated P2P trading mechanism and the BESS operation mechanism. Section 4 presents the emerging UDDSR system and the optimization approach. Section 5 demonstrates the effectiveness of the proposed EMS with two case studies, and the conclusion is drawn in section 6 .

\section{System Infrastructure}

\section{A. Overview of the Proposed EMS}

Considering the local users installed with renewables, EVs and BESS in the secondary distribution network, a schematic diagram of such network associated with the proposed EMS and energy pool is presented in Figure 1. The information flow (dashed lines in Figure 1) transmit the distribution network status, DR request, price signals and control signals among network operators, EMS, energy pool and end users. The local energy pool, a trading and transaction system, is used as a local energy market for trading the surplus energy and BESS stored energy in local network among neighbourhoods. The EMS, a coordinator between network operator and end users, will exchange the DR information between network operator and the domestic users to help dispatch the DR event. It should be noted that the EMS will not involve in the daily operation and energy trading of end users except when the DR events are triggered. When a DR request is generated by network operator (e.g. in the circumstance that a voltage violation is detected in the distribution network by the network operator SCADA), the EMS will broadcast the DR request to the end users once the request is received from network operator. After collecting the bids from the end users, the EMS will schedule the bids to ensure the dispatching of the DR event and report the aggregated demand to network operator. If the network operator agrees the dispatching of the aggregated demand after completing the congestion calculation or security analysis, the operator will release the dispatching command to EMS in advance, and the EMS will let end users to execute the DR event. During the DR event, the EMS will monitor if the agreed demand is actually delivered by the end users and subsequently report the states of DR execution to the network operators before any transaction is processed.

In addition, to ensure the UDDSR program is executed properly, a framework entitled "smart energy hub" (S.E. $\mathrm{Hub}$ ) is adopted, which has been presented in [21-23]. Each domestic user can be represented as a single S.E.Hub that has bi-directional communication capability in the cloud computing infrastructure. In the proposed S.E.Hub framework, the SE.Hub is able to communicate with both the Gas and Electricity utilities/operators. Since only electricity is considered in this paper and there is an EMS between the end users and the network operator, we assume the EMS will act as a gateway between them to enable the information exchange but under a same framework.

\section{B. User Dominated Demand Side Response System}

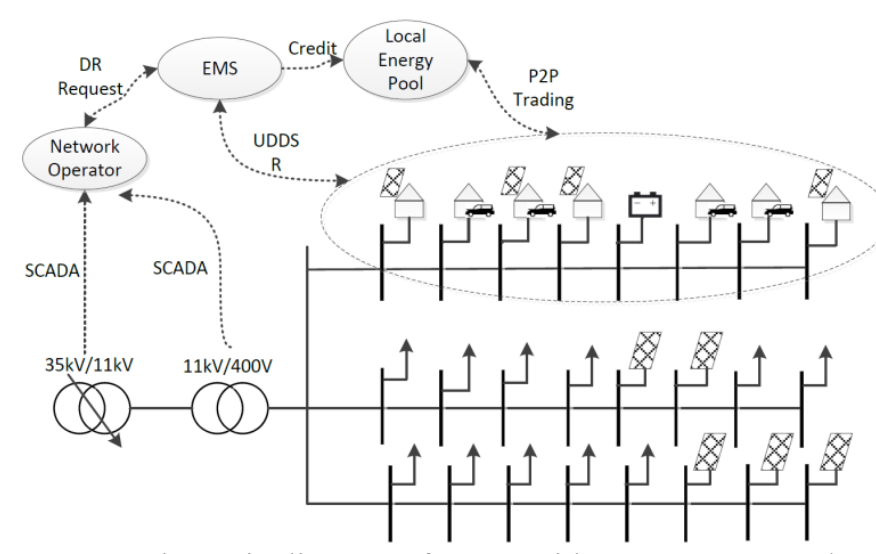

Fig. 1. Schematic diagram of smart grid system composed of EMS and local energy pool

Extensive research has been conducted on designing DR program and the associated optimization algorithms. Most of research activities assume the interruptible loads/generators will respond to the DR event in a full cycle once they accept the DR requests. Some research considers the availabilities of interruptible devices and the user comfortabilities during the DR events but the common way they adopted to maintain the user comfortabilities is using the user comfort zone as the constraints when scheduling the interruptible devices for DR events. There is very limited research investigating the scenario that users partially roll into the DR event for a certain period of time which is highly likely to happen in reality (e.g. a heating system can be turned off for five minutes without causing any discomforts to users, but thirty minutes' or an hour's interruption of heating system will surely disturb users' comfort).

Table 1 Customer Bidding Format

\begin{tabular}{ccc}
\hline Symbol & Description & Units \\
\hline ID & User ID & N/A \\
$T 1$ & Earliest starting time & $(\mathrm{min})$ \\
$T 2$ & Latest ending time & $(\mathrm{min})$ \\
$D$ & Maximum interrupting durations & $($ mins $)$ \\
$S$ & Type of appliances & $0=$ 'interruptible' \\
& & $1=$ 'shiftable' \\
$P$ & Power of interrupted device & $(\mathrm{kW})$ \\
\hline
\end{tabular}

Therefore, a UDDSR program aiming at maximizing the flexibilities of DR participants is proposed in this paper. The proposed program allows users to submit flexible bids for DR events following the format shown in Table 1. The bid includes the earliest starting time and latest ending time of users' interruptible devices, the maximum sum of interruption durations within one DR event and the power of their appliances. The symbol ' $S$ ' denotes the type of appliances. UDDSR divides the appliances into two categories: 1) interruptible appliances (e.g. heating system) and 2) shiftable appliances (e.g. EV and wash machine). The interruptible appliances allow UDDSR to turn them off within the allowable duration instead of shifting the demand to a later time slot. For shiftable appliances like EV, UDDSR will shift the charging activity to a later time slot. It should be noted that we assume the local EV owners have their own smart home EMS and the EMS will be able to optimize the scheduling of EV charging on their own once their bids to UDDSR are accepted. 


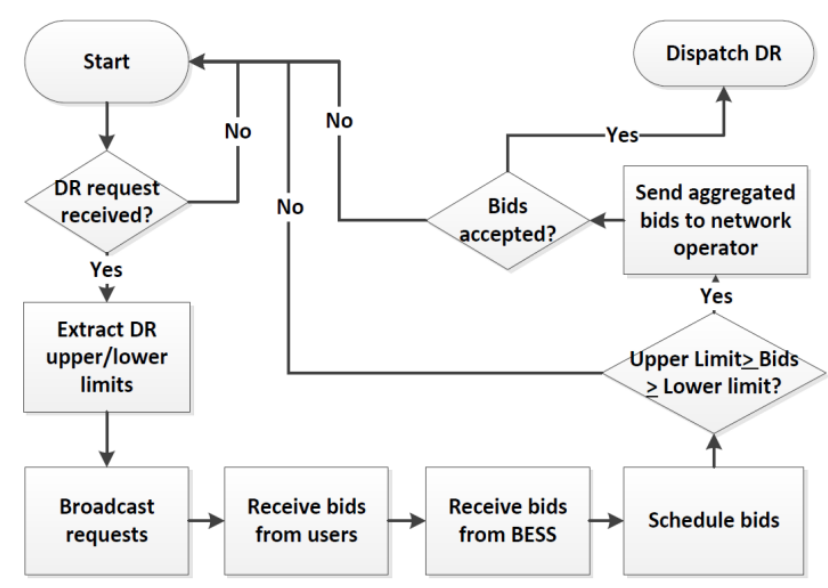

Fig. 2. UDDSR flow chart

The EMS acts as the aggregator for the DR event. The whole process of executing one UDDSR event is presented as in Figure 2. Once the EMS receives the request from the network operator, the EMS will broadcast the DR request (including event start/end timestamps, DR price per $\mathrm{kWh}$ and the upper/lower limits of DR request received from system operator) to the DR participants. DR participants will decide if they will participate in the event regarding to their availabilities. If they decide to participate into the DR event, they will submit their flexible bids to EMS. Each participant is allowed to submit more than one bid regarding to the number and power of interruptible appliances. Participants can also submit an aggregated bid to EMS. All the bids submitted by participants should follow the format shown in Table I. After receiving all the bids from participants, the EMS will schedule the participants' bids and pack an aggregated DR bid whose power at each time interval of the DR event bid is even. If the scheduled bids are larger than the upper limits or lower than the lower limits, the EMS cannot process the DR request. Otherwise, the aggregated bid will be sent to the network operator by the EMS. If the aggregated bid is accepted by network operator, the EMS will broadcast the fixed DR request with appliance operation schedule to every selected participant. After dispatching the operation schedule, participants will be credited by the EMS through the proposed energy pool transaction system. Since this paper does not focus on the ancillary service market research, we assume the network operator will always accept the aggregated bids if they are within the upper and lower limits.

\section{Local Energy Pool}

The local energy pool is used to facilitate the usage of surplus renewable generations by allowing the trading among neighborhoods. Energy end users join the energy pool voluntarily and are assumed to accept an in-common market clear price decided by the surplus-to-demand ratio. An electricity pricing model is proposed in [17] as follows, including one external element the real-time TOU price $d(t)$ referring to the wholesale market price or the contracted TOU and one internal element $q\left(t, P_{n}(t)\right)$ regarding to the aggregated local energy profile:

$$
\lambda\left(t, P_{n}(t)\right)= \begin{cases}d(t)+q\left(t, P_{n}(t)\right) & , P_{n}(t)>0 \\ d(t)-q\left(t, P_{n}(t)\right) & , P_{n}(t) \leq 0\end{cases}
$$

s.t.

$$
q\left(t, P_{n}(t)\right)=a(t) \cdot\left|P_{n}(t)\right|^{2}+b(t) \cdot\left|P_{n}(t)\right|+c(t)
$$

where $a(t), b(t)$ and $c(t)$ are time-dependent nonnegative parameters and $P_{n}(t)$ denotes the aggregated local load profile.

The price model (1) assumed that end users are willing to pay a higher price than market price when there is positive aggregated load profile. One of the users' key motivations to participate in such a program is to save on electricity bills, however, users in a less DER penetrated network will possibly pay a higher bills when deploying such model [24]. To enhance users' motivations, a surplus-vs-demand based pricing model that ensures a lower price than market price is proposed in this paper as below:

$$
\begin{array}{cc} 
& \lambda\left(t, \gamma_{n}(t)\right)=d(t)-q\left(t, P_{n}(t)\right) \\
\text { s.t. } & q\left(t, \gamma_{n}(t)\right)=a(t) \cdot \gamma_{n}(t)^{2}+b(t) \cdot \gamma_{n}(t) \\
& \left\{\begin{array}{c}
q\left(t, \gamma_{-} n(t)\right)+p^{F}<d(t), \text { if } d(t)>p^{F} \\
d(t)-q\left(t, P_{n}(t)\right)=p^{F}, \text { if } d(t) \leqslant p^{F}
\end{array}\right. \\
& \gamma_{n}(t)=p_{m}(t) / p_{(n-m)}(t)
\end{array}
$$

where $\gamma_{n}(t)$ denotes the ratio of the aggregated supplier and demand at time $t$ in the energy pool, $p_{m}(t)$ denotes the aggregated amount of energy that $m$ users are selling to the pool, $p_{(n-m)}(t)$ denotes the aggregated demand amount of the left $(n-m)$ users that are requesting energy from the pool, $p^{F}$ denotes the Feed-in-Tariff (FIT).

Equation (4) is considered as a dynamic price function that has been discussed in [25]. Equation (5) is to ensure the sum of dynamic pricing part (related to the surplus-vsdemand ratio) and the Feed-in-Tariff price should be always lower than the contracted electricity retail price, when the retail price is higher than the FIT. When retail price is lower than FIT, the pool price will be equal to the FIT. The proposed pricing model would be able to maintain the electricity price of the energy pool lower than the market price but higher than the FIT.

The credit/bill of customers who participate in the energy pool will be calculated by EMS using equations (7-8) after clearing the energy pool at the end of each dispatch interval.

$$
C_{i}(t)= \begin{cases}\lambda\left(t, \gamma_{n}(t)\right) \cdot e_{i}(t) & , e_{i}(t) \geq 0 \\ -\lambda\left(t, \gamma_{n}(t)\right) \cdot e_{i}^{B}(t)-d(t) \cdot\left(e_{i}(t)-e_{i}^{B}(t)\right), & e_{i}(t)<0\end{cases}
$$

s.t.

$$
e_{i}(t) \geq e_{i}^{B}(t)
$$

where $C_{i}(t)$ denotes the credit $\left(C_{i}(t) \geq 0\right)$ or bill $\left(C_{i}(t)\right.$ $<0)$ of participant $i$ at time $t, e_{i}(t)$ denotes the energy feed into/ purchase from the grid of participant $i ; e_{i}^{B}(t)$ denotes the energy bought from energy pool.

Since we focus on the pricing mechanism of the local energy pool, the computation for clearing the market or adjusting the price based on real-time information are not included, but this is an important part in the energy pool research and will be performed in the future research work.

\section{Battery Energy Storage System}

BESS or Distributed Storage System (DSS) is considered as the key equipment in future microgrids [26-29]. It is assumed that a BESS is included in the proposed microgrid and follows the model and constraints described below [26, 
27]:

$$
E_{(t+\Delta t)}^{B t}= \begin{cases}E_{t}^{B t}+P_{t}^{b} \cdot \eta^{c} \cdot \Delta t & \text { if } P_{t}^{b} \geq 0 \\ E_{t}^{B t}+\frac{P_{t}^{b}}{\eta^{d}} \cdot \Delta t & \text { if } P_{t}^{b}<0\end{cases}
$$

s.t.

$$
\begin{gathered}
P_{d}^{b} \leq P_{t}^{b} \leq 0 \text { if } P_{t}^{b}<0 \\
0 \leq P_{t}^{d} \leq P_{c}^{b} \text { if } P_{t}^{b} \geq 0 \\
0 \leq E_{t}^{B t} \leq E^{B t}
\end{gathered}
$$

where $E_{(t)}^{B t}$ is the capacity of BESS at time $t, P_{t}^{b}$ is the charging/discharging rate of BESS at time $t, \eta^{c}$ is the charging efficiency, $\eta^{d}$ is the discharging efficiency, $P_{c}^{b}$ is the BESS maximum charging rate, $P_{d}^{b}$ is the BESS maximum discharging rate and $E^{B t}$ is the maximum BESS capacity.

The BESS within the microgrid will participate in the energy pool transactions aiming to maximize its profits by arbitrage trading. The objective function of BESS can be described as below:

$$
\operatorname{Max} \sum_{t=1}^{N} P_{t}^{b} \cdot \lambda\left(t, \gamma_{n}(t)\right)
$$

The objective function of BESS relates to real-time energy pool price (3) and should satisfy the equations (912). The optimization of BESS operation is a MILP problem and can be solved by most market-available solvers (e.g. IBM CPLEX and Gurobi). Since the energy pool price is determined by the surplus-vs-demand ratio, the profit will be influenced by an inappropriate scheduling of BESS operation resulting from the error of the forecasting surplus generation and energy demand [27]. Model Predictive Control (MPC) can be adopted, which have been widely used in microgrid management to minimize the influence of forecasting error of generation and demands and to achieve promising performance $[14,27,29,30]$.

\section{UDDSR OPTIMIZATION AND OPERATION}

Section 2 has presented the system infrastructure of a community with a local energy pool, and the pricing mechanism of the pool has been discussed. The mechanism of the proposed UDDSR program has also been presented in the previous section. In this section, the detailed optimization of the proposed UDDSR is performed and associated operation approach is presented.

\section{A. UDDSR Optimization Approach}

Since the offers of each DR participant are start/stop flexible, EMS will be in charge of scheduling the bids to maximize the usage of received bids and make sure the aggregated bids at every time interval within the DR event should be even (which makes the load reduction amount during the DR event is constant). The optimal scheduling of DR offers will be achieved once the profit (allocated power) at each time interval $t$ of the DR event will not increase by increasing or shifting the allocable power at/among any DR time intervals. This can be described as the objective function below.

$$
\begin{gathered}
\operatorname{Max} E^{D}(t)=\sum_{i=0}^{N} \mathrm{P}_{i} \cdot b_{i}(t) \quad t \forall T \\
\operatorname{Max} E^{D}(t+1)=\sum_{i=0}^{N} \mathrm{P}_{i} \cdot b_{i}(t) \quad t \forall T
\end{gathered}
$$

$$
\operatorname{Max} E^{D}(t+T)=\sum_{i=0}^{N} \mathrm{P}_{i} \cdot b_{i}(t) \quad t \forall T
$$

s.t.

$$
\sum_{t=0}^{T} \mathrm{P}_{i} \cdot b_{i}(t) \leq E_{i} \quad i \forall N
$$

where $E^{D}(t)$ denotes the sum of scheduled power at time interval $\mathrm{t}$ during the $\mathrm{DR}$ event, $\mathrm{P}_{i}(t)$ denotes the rating power of participant's appliance, $b_{i}(t)$ is a binary value denoting the scheduling of the appliances (appliance $=\mathrm{OFF}$ if $b_{i}(t)=1$ and appliance $=\mathrm{ON}$ if $\left.b_{i}(t)=0\right)$.

Regarding equation (14) and the market mechanism, it is obvious that the complexity of solving this multi-objective function (maximizing the flexible loads in every time interval and making the allocated loads at every time interval as balanced as possible) will increase along with the increase of time resolution used in the DR event time interval, and the total profit of the whole DR event will be decided by the minimum allocated power of all time interval $t$ within the DR event. Thus, to reduce the complexity of the optimization problem, the multi-objective function is transformed into a single objective function by introducing the variation of allocated power at each time interval $t$ during the DR event.

To simplify the multi-objective function, the multiobjective optimization problem can be firstly re-written as a dual-objective function as below.

$$
\begin{gathered}
\operatorname{Max} \sum_{i=1}^{N} \sum_{t=1}^{T} \mathrm{P}_{i} \cdot b_{i}(t) \\
\operatorname{Min} \operatorname{VAR}\left(E^{D}(t)\right)
\end{gathered}
$$

where equation (16) is to maximize the allocated power during the whole DR event, and equation (17) is to minimize the variation of allocated power at every time interval of the whole DR event.

By introducing a penalty factor $\delta$, a single objective function can be formulated as below:

$$
\operatorname{Max}\left(\sum_{i=1}^{N} \sum_{t=1}^{T} \mathrm{P}_{i}(t) \cdot b_{i}(t)-\delta \cdot \operatorname{VAR}\left(E^{D}(t)\right)\right)
$$

The penalty factor $\delta$ is to increase/decrease the impact of balancing the allocated power at the time interval for the objective function. The objective function should also satisfy the following constraints.

$$
\begin{aligned}
& \sum_{i=1}^{N} \sum_{t=1}^{T} \mathrm{P}_{i}(t) \cdot b_{i}(t) \leqslant E_{U L} \\
& \quad \sum_{i=1}^{N} \sum_{t=1}^{T} \mathrm{P}_{i}(t) \cdot b_{i}(t) \geq E_{L L}
\end{aligned}
$$

Where $E_{U L}$ denotes the upper limit of DR scheme, and $E_{L L}$ denotes the lower limits of DR scheme.

To solve the objective function (18), since there are nonlinear elements within the functions, and the control variables of shiftable/interruptible loads are integer variables, the optimization problem of (18) is a MILP problem, which can be solved by most market-available solvers (e.g. Gurobi, CPLEX and CBC).

\section{B. UDDSR Optimization with BESS}

The operation of BESS will be different from the users' interruptible loads (e.g. electric heaters) and shiftable loads (e.g. EV) during UDDSR events. This is due to the fact that BESS can perform charging (as a load) and discharging (as an energy source) activities in different time intervals within 
one DR event. The total profit of the DR event in local network can be improved by compensating the power of time intervals with less available offers or/and shaving the power of time intervals with sufficient offers using BESS.

The objective function of the UDDSR optimization remains unchanged after introducing the BESS into the DR event. In the meantime, the operating constraints of BESS, i.e. equation (9-12), should be added into the optimization. It should be noted that the time interval of the UDDSR event is usually much smaller than the conventional DR event, which could lead to a relatively high frequency of switching the charging/discharging direction of BESS during the UDDSR event. Frequently changing the power flow directions of BESS will reduce the lifetime of capacitors, IGBT and other components inside the BESS inverters. The operation constraints of BESS during UDDSR event is described as follows.

$$
\sum_{t=0}^{N^{\prime}-1}\left(S_{t}^{B} * S_{t+1}^{B}\right) \geq \omega, \mathrm{t} \forall N^{\prime}
$$

s.t.

$$
\left\{\begin{array}{c}
S_{t}^{B}=-1 \text { when } P_{t}^{b} \geq 0 \\
S_{t}^{B}=1 \text { when } P_{t}^{b}<0
\end{array}\right.
$$

where $S_{t}^{B}$ denotes the charging/discharging state of BESS, and $N$ ' denotes the number of time intervals in one UDDSR events, $\omega$ denotes the power flow changing frequency of every two intervals during certain duration of DR event. The presence of Equation (21) and (22) is to maintain the changing frequency of charging/discharging power flow direction during the UDDSR events. To further explain the effects of these two equations, when the operation states (no matter charging or discharging) of BESS keep same in every time interval during the whole DR event, the value of $\sum_{t=0}^{N^{\prime}-1}\left(S_{t}^{B} * S_{t+1}^{B}\right)$ will always be $\mathrm{N}^{\prime}-1$, which is only related to the number of time intervals of DR event. When the power flow direction of BESS changes (charging changes to discharging or discharging changes to charging) during DR event, the value of $S_{t}^{B} * S_{t+1}^{B}$ at the time interval which power flow changes will be -1 . If the BESS operational state changes $\mathrm{x}$ times during the DR event, the value of $\sum_{t=0}^{N^{\prime}-1}\left(S_{t}^{B} * S_{t+1}^{B}\right)$ will be (N-1-x*2), which can be used to regulate the changing frequency of BESS operational states during the DR event in Equation (21).

\section{Crediting Participants of UDDSR event}

Customers who participate into the UDDSR event will be credited by the network operator or DR agent according to their contributions. In order to keep motivating the customers, it is assumed that the unit price of subsidy allocated to customers is higher than the electricity price during the day. The subsidy for BESS is different from that for the normal customers, it is calculated based on the sum of absolute value of charging and discharging amount. The subsidy for the customers and BESS are given as follows.

$$
\begin{gathered}
C_{i}^{U}=\sum_{t=0}^{N^{\prime}} \chi * P_{i}(t), t \forall N^{\prime} \\
C_{B}^{U}=\sum_{t=0}^{N^{\prime}} \chi_{B} *\left|P_{B}(t)\right|, t \forall N^{\prime}
\end{gathered}
$$

where $C_{i}^{U}$ denotes the credit allocated to participant i, $\chi$ denotes the unit price of subsidy for normal participants,
$C_{B}^{U}$ denotes the credit allocated to BESS, $\chi_{B}$ denotes the unit price of subsidy for BESS.

It should be noted that both charging and discharging activities of BESS are counted as contributions to the DR event, and hence are rewarded accordingly.

\section{CASE STUDIES}

Simulations are performed to test the validity of the proposed local energy pool system and the proposed UDDSR mechanism. The quantitative analysis of the electricity cost for residents within the energy pool is presented in this section. The performance of the proposed UDDSR and the earnings of participants obtained from UDDSR are discussed. The potential of using BESS to participate into the UDDSR is also analysed. For the modelling of the energy pool and the UDDSR scheme, Python is selected as the programming language and Gurobi is used as the optimization solver. Other python statistical libraries including Pandas, Numpy and Matplotlib are used. The program runs on a computer with Intel Core i7@ 3.40GHz CPU and 16GB RAM.

\section{A. Case I : Smart Community with Local Energy Pool}

The proposed energy pool is free to join for all users within the community. The price of the energy pool is related to the wholesale market price as well as the demand/supply ratio within the community.

To evaluate the performance of the proposed energy pool, a community with 50 domestic users is used as the test bed. The hourly electricity load profile of the domestic users and the PV generation profile are collected from the Low Carbon London project, whose data are available on the website London Datastore. Aiming to perform a comprehensive analysis on the energy pool, the PV penetration levels of the community at $20 \%, 50 \%$ and $100 \%$ are respectively analysed. For the proposed penetration level, it is calculated based on the percentage of domestic users who installed the roof PV generators each with rating power $3.2 \mathrm{~kW}$ (e.g. for $20 \%$ penetration level, there will be 10 domestic users installed with $3.2 \mathrm{~kW}$ roof PV generator). The wholesale market price is collected from the EPEX dayahead market.

Figure 3 presents the comparison of the energy pool price and the wholesale market price when the PV penetration is $20 \%$ in the community over one week. It can be found that the pool price is lower than the wholesale market price at the most time, and the pool price is determined by the demand/supply ratio within the community. When the wholesale market price is lower than the preset lower limit of the energy pool, the pool clearing price will maintain at the lower limit to secure the profitability of the PV owners. 


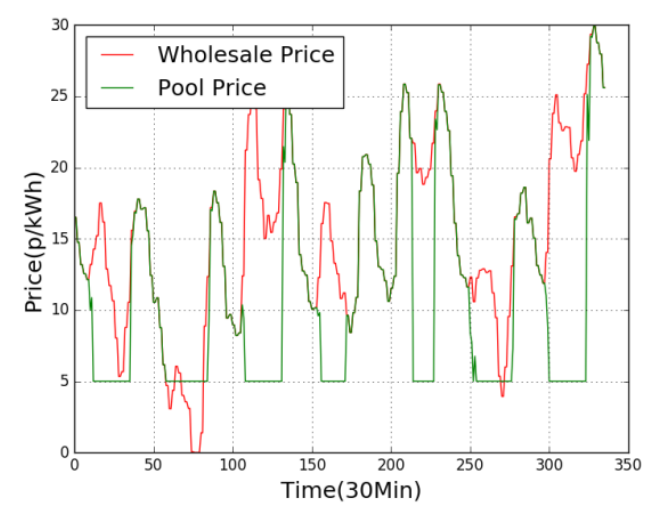

Fig. 3. Clearing price of $\mathrm{P} 2 \mathrm{P}$ energy pool vs wholesale price over one week

To further analyse if the participants can profit from the energy pool, numerical analysis on the domestic users' bills is performed. The table of detailed domestic bills using wholesale market price and local energy pool is attached in Appendix part A. Table 2 provides a summary of the savings generated from the energy pool.

Table 2 Numerical Summary of P2P Energy Pool

\begin{tabular}{|c|c|c|c|}
\hline & $\begin{array}{c}\text { Average } \\
\text { Saving(\%) }\end{array}$ & $\begin{array}{c}\text { Maximum } \\
\text { Saving(\%) }\end{array}$ & $\begin{array}{c}\text { Minimum } \\
\text { Saving(\%) }\end{array}$ \\
\hline $\begin{array}{c}\text { Domestic } \\
\text { with PV }\end{array}$ & 184.8 & 371.1 & 8.1 \\
\hline $\begin{array}{c}\text { Domestic } \\
\text { without PV }\end{array}$ & 6.16 & 11.1 & -3.467 \\
\hline
\end{tabular}

From Table 2, it can be found that the domestic users without PVs benefit from a $6.16 \%$ savings on average on their electricity bills after joining the energy pool. 39 out of 40 domestic users without PV can get savings by joining the energy pool and the maximum saving percentage can reach $11.1 \%$. Only one of them get a negative savings, who will pay $3.467 \%$ more than the bills calculated based on wholesale market price. For the 10 domestic users with PV, the profitability has been significantly improved. The average profitability for them increased by $184.8 \%$ after joining the energy pool and one of them received an saving of $371 \%$. The significant increase in the profitability is because the PV owners can sell their surplus electricity to their neighborhoods during the relatively high-price period, and the demand/supply ratio is relatively high on in this scenario (20\% penetration), which helped the PV owners secure a good return on their investment.

To comprehensively evaluate the energy pool performance, $50 \%$ and $100 \%$ PV penetration levels are also adopted. The tables of detailed domestic bills using wholesale market price and local energy pool at 50\% and $100 \%$ penetration level are attached in Appendix part A. The summarized table describing the energy pool is given in table 3 .

Table 3 Bill Savings at 50\% and 100\% Penetration Level

\begin{tabular}{|c|c|c|c|}
\hline & $\begin{array}{c}\text { Average } \\
\text { Saving(\%) }\end{array}$ & $\begin{array}{c}\text { Maximum } \\
\text { Saving(\%) }\end{array}$ & $\begin{array}{c}\text { Minimum } \\
\text { Saving(\%) }\end{array}$ \\
\hline $\begin{array}{c}\text { Domestic with } \\
\text { PV ( 50\% } \\
\text { Penetration) }\end{array}$ & 44.75 & 127.8 & 6.28 \\
\hline Domestic & 17.7 & 23.7 & -2.65 \\
\hline
\end{tabular}

\begin{tabular}{|c|c|c|c|}
\hline $\begin{array}{c}\text { without PV (50\% } \\
\text { Penetration) }\end{array}$ & & & \\
\hline $\begin{array}{c}\text { Domestic (100\% } \\
\text { Penetration) }\end{array}$ & 13.4 & 23.69 & 0.005 \\
\hline
\end{tabular}

For the scenario of $50 \% \mathrm{PV}$ penetration, compared to the scenario of $20 \%$ PV penetration, the average profitability of domestic users with PV has decreased while the average savings of domestic users without PV has increased. Resulting from the decrease of the demand/supply ratio within the community, the PV owners faced competitions with other PV owners within the community, which correspondingly decrease the sale price of the electricity within the energy pool. However, it is certain that both the domestic users with and without PV benefit from the local energy pool. When the PV penetration level at the local community reaches $100 \%$, there are no pure consumers or producers but the prosumers within the community. All the residents within the community can trade with each other, the average saving/ profitability increase are still at a reasonable level (equals to 13.4\%) through the proposed energy pool pricing strategy. In such kinds of environments, it is more important to ensure the participants can secure reasonable benefits from the energy pool. If a small number of the domestic users occupy large percentages of the benefits, it will seriously influence the motivations of other domestic users in participating in the energy pool. Thus, it is necessary to investigate the distribution of the saving percentages of the prosumers. The distribution of the saving percentages of 50 domestics is shown in Figure 4. It is obvious that the most saving percentages are located between $6-12 \%$, and only a very small number of domestic users can get high percentage savings.

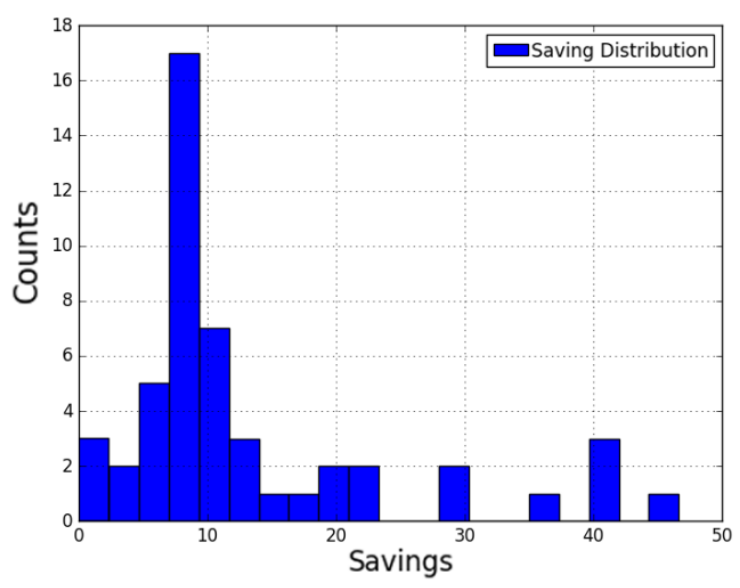

Fig. 4. Saving percentage distribution of 50 domestics at $100 \%$ PV penetration level

According to the analysis above, it can be concluded that the proposed energy pool has reasonable performance at different PV penetration levels of the community. Both domestic users with and without PV can benefit from the proposed scheme. The PV owners can profit at any penetration levels, even at $100 \%$.

\section{B. CASE II : Smart Community with Local Energy Pool and UDDSR (without BESS)}

The proposed UDDSR allows participants to submit the 
demand response bids with customised drop-in and drop-out time. They can also define the length of time period they want to respond during the whole DR event. Such design promises significant flexibility to the participants, and can correspondingly facilitate the DR program in theory. However, it is still important to evaluate if the proposed UDDSR scheme can effectively schedule the customer bid to achieve the maximum use of customer controllable resources.

To evaluate the proposed UDDSR, a comprehensive numerical analysis for the UDDSR with/without BESS is conducted in this section. It should be noted that the customer bidding format will only contain starting time, ending time and total response duration rather than the full information biding format given in Table I from simplification purpose point of view. We also assume all the customer will have the same response rating power during the test, the time interval used in the test is 5 minutes and the DR event duration is 1 hour. The table of detailed bidding information of 50 domestic users is attached in Appendix Part B.

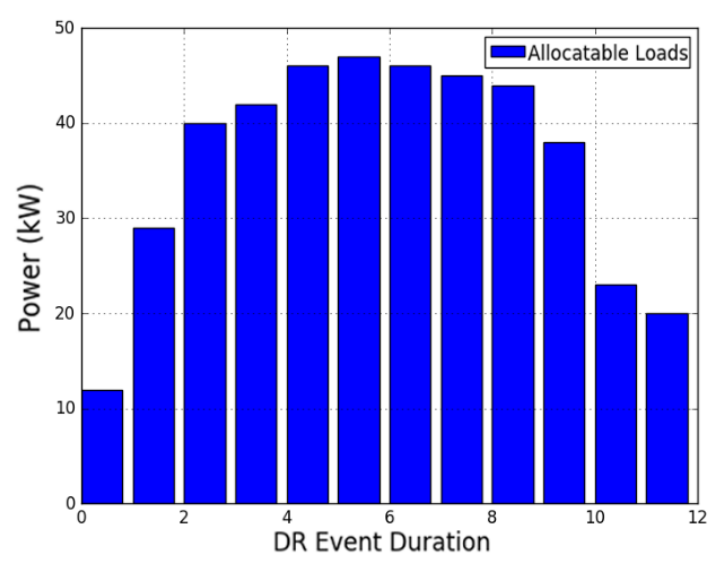

Fig. 5. Maximum allocable loads during DR event

Figure 5 presents the maximum allocable loads in every time interval of DR event that are submitted by the participants. The proposed UDDSR solving approach is to schedule the operation of customer bid to achieve a maximum use of customers' flexible resources, and the scheduling for part of the customers are given in Figure 6. The dark grey part is the scheduled time slot for every participant. The $\mathrm{y}$ axis represents the 50 homes and the $\mathrm{x}$ axis represents 12 time intervals during one DR event. It is found that the scheduled power at every time interval is $12 \mathrm{~kW}$, equals to $12 \mathrm{kWh}$ in the whole DR event (if the DR event lasts 1 hour). Compared with the total allocable energy $21.2 \mathrm{kWh}$, only $56.7 \%$ energy are scheduled during the DR event. This is because the allocable energy at time interval 1 is significantly less than the energy at other time intervals.

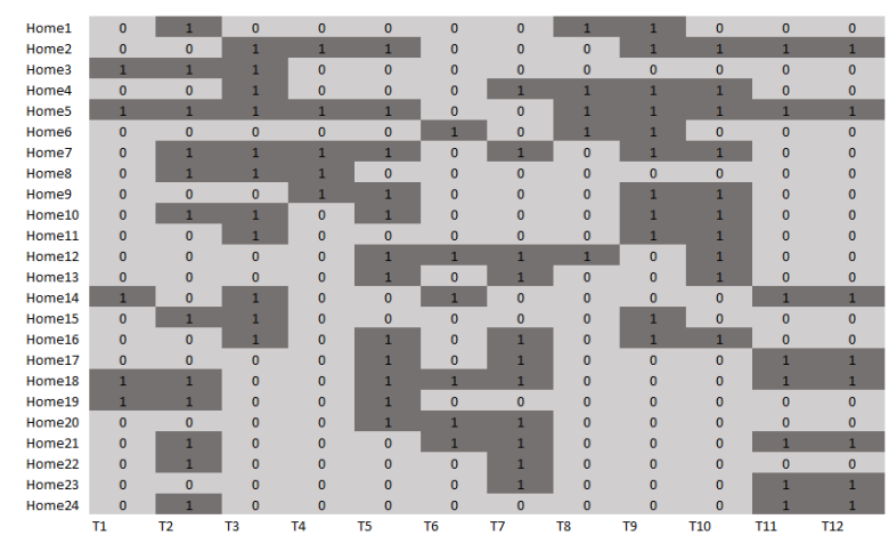

Fig. 6. Scheduling of selected customers

If the imbalance of different time intervals can be reduced, the load scheduling efficiency can be improved. To reduce the imbalance, there are two approaches can be adopted: one is to encourage customers to allocate more shiftable energy to the time interval that is in electricity shortage by paying more subsidy to the specific time interval, the other way is introduced the BESS or other types of energy storage system to compensate the specific time intervals. Both approaches are evaluated in the following part.

Since the focus of this paper is not on the incentive design, the load scheduling during DR event is evaluated by increasing the allocable energy at the time interval when electricity is in shortage rather than investigating the pricing strategy of the subsidy. The modified allocable loads at different time intervals is shown in Figure 7 (The table of detailed bidding information of 50 domestic users in improved imbalance situation is attached in Appendix Part B).

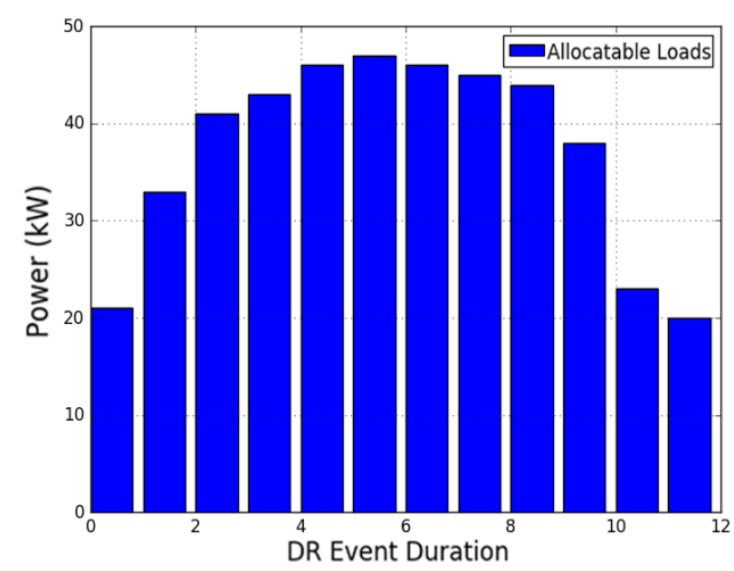

Fig. 7. Maximum allocable loads during DR event with improved imbalance

The scheduled power at each time interval can be increased to $20 \mathrm{~kW}$ if the imbalance can be improved without changing the total allocable energy of $21.2 \mathrm{kWh}$. $94.3 \%$ of the total allocable energy has been successfully scheduled in this scenario, which has significantly improved the imbalance situation.

To fully investigate the proposed UDDSR, the BESS is introduced for evaluation purpose. The BESS adopted in this study is with a maximum charging/discharging power of $25 \mathrm{~kW}$, a capacity of $50 \mathrm{kWh}$ and an initial State of Charge 
(SOC) at 0.4 . The $\omega$ introduced in equation (21) was set to 1 , which indicates that the BESS cannot change the operational states five times during 12 time intervals of one DR event. The customer bids information follows the information in Figure 5 in a seriously imbalanced situation. The scheduled power of customers and BESS is given in Figure 8 below.

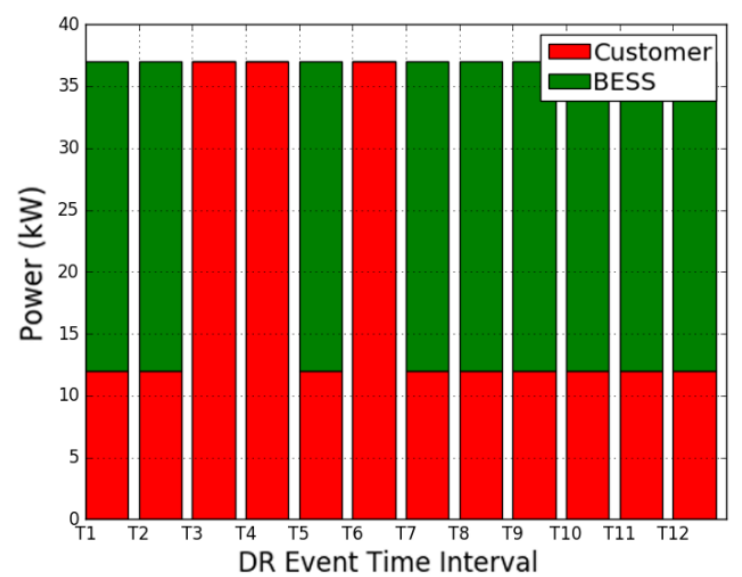

Fig. 8. Power scheduling with BESS

From Figure 8, the BESS, according to Figure 8, was almost continuously charged at the maximum power in order to compensate the customer loads during time interval t3, t4 and t6. $86.1 \%$ of the allocable loads (18.25 out of $21.2 \mathrm{kWh}$ ) of customers are allocated during the whole DR events, which consequently improved the scenario without BESS. The BESS contributed $18.75 \mathrm{kWh}$ to the DR event.

However, the BESS SOC can be at any level when the DR event invokes. It is necessary to investigate if the BESS can still contributes to the DR event when the BESS is at high SOC level.

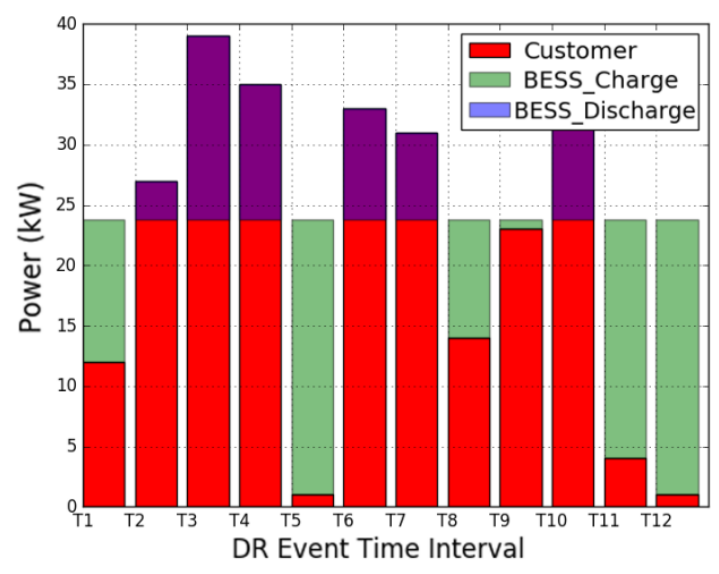

Fig. 9. Power scheduling with BESS at high SOC

Figure 9 presents the allocation of customer loads as well as the operation of the BESS when the BESS is at high $\mathrm{SOC}=0.9$. The green bar indicates the BESS charging state and the purple bar indicates the BESS discharging state. The allocable loads $(21.2 \mathrm{kWh})$ has been $100 \%$ fully scheduled under this scenario benefiting from the compensation of BESS. The BESS charged $7.31 \mathrm{kWh}$ and discharged $4.7 \mathrm{kWh}$ during the DR event. The allocation of the power at every time interval is even, which can provide a smooth load reduction during the DR event.
According to the analysis in section 4, it can be concluded that the proposed UDDSR can make good usage of customer flexible loads if the distribution of the loads is at a reasonable balance level for different time intervals of the whole DR event. When the customer flexible loads are distributed seriously imbalance, the usage of customer loads is not in a high level. When the BESS is introduced into the DR event, the customer flexible loads can be significantly improved at all BESS's SOC levels.

\section{CONCLUSION}

This paper has presented a P2P trading model and the UDDSR scheme for local communities. The P2P trading infrastructure and pricing model can facilitate the electricity trading within the community. The consumers, producers and prosumers within the community can all get certain benefits from the P2P trading infrastructure. The pricing of the local energy pool is determined based on the demand/supply ratio, and a minimum pricing guarantee (equal to or higher than FIR) is included. From the numerical analysis on the energy pool, the consumers can get a minimum $6.16 \%$ savings on their bills at different PV penetration levels. For the prosumers that installed with PV, the profitability has been significantly improved (a minimum $13.4 \%$ increase on the return of investment of roof PV among three different scenarios). To further improve the participants' flexibilities and comfortabilities, the proposed UDDSR is proposed that allow participants make flexible DR bids with flexible start/stop time and customized participated duration. Such design promise great flexibility to the customers, which can help the DR scheme providers promote the DR scheme in an easy way. The numerical analysis on UDDSR shows that the proposed UDDSR can schedule the customers' flexible loads properly if the loads are distributed in a balance state based on the proposed UDDSR optimization approach. If the DR bids is in a seriously imbalance state, the BESS is considered to help the DR load balancing among small intervals during DR event. It is found that the usage efficiency of customers' flexible loads can increase from $56.7 \%$ to $86.1 \%$ with the assistance of BESS in the seriously imbalance state.

\section{References}

[1] N. Rahbari-Asr and M.-Y. Chow, "Cooperative distributed demand management for community charging of PHEV/PEVs based on KKT conditions and consensus networks," IEEE Transactions on Industrial Informatics, vol. 10, pp. 1907-1916, 2014.

[2] Z. Li, J. He, J. Teng, and Y. Wang, "Internal stress monitoring of in-service structural steel members with ultrasonic method," Materials, vol. 9, p. 223, 2016.

[3] F. Rahimi and A. Ipakchi, "Demand response as a market resource under the smart grid paradigm," IEEE Transactions on Smart Grid, vol. 1, pp. 82-88, 2010.

[4] B. Greening and A. Azapagic, "Domestic heat pumps: Life cycle environmental impacts and potential implications for the UK," Energy, vol. 39, pp. 205-217, 2012.

[5] E. Xydas, C. Marmaras, L. M. Cipcigan, A. Hassan, and N. Jenkins, "Forecasting electric vehicle charging demand using support vector machines," in Power Engineering Conference (UPEC), 2013 48th International Universities', 2013, pp. 1-6. 

"Plug-in hybrid electric vehicle charge pattern optimization for energy cost and battery longevity," Journal of power sources, vol. 196, pp. 541-549, 2011.

[7] S. Chen, Y. Ji, and L. Tong, "Large scale charging of electric vehicles," in Power and Energy Society General Meeting, 2012 IEEE, 2012, pp. 1-9.

[8] S. Stüdli, E. Crisostomi, R. Middleton, and R. Shorten, "A flexible distributed framework for realising electric and plug-in hybrid vehicle charging policies," International Journal of Control, vol. 85, pp. 1130-1145, 2012.

[9] Z. Tan, P. Yang, and A. Nehorai, "An optimal and distributed demand response strategy with electric vehicles in the smart grid," IEEE Transactions on Smart Grid, vol. 5, pp. 861-869, 2014.

[10] D. Wang, S. Parkinson, W. Miao, H. Jia, C. Crawford, and N. Djilali, "Online voltage security assessment considering comfort-constrained demand response control of distributed heat pump systems," Applied Energy, vol. 96, pp. 104-114, 2012.

[11] D. Papadaskalopoulos, G. Strbac, P. Mancarella, M. Aunedi, and V. Stanojevic, "Decentralized participation of flexible demand in electricity markets-Part II: Application with electric vehicles and heat pump systems," IEEE Transactions on Power Systems, vol. 28, pp. 3667-3674, 2013.

[12] J. H. Yoon, R. Baldick, and A. Novoselac, "Dynamic demand response controller based on real-time retail price for residential buildings," IEEE Transactions on Smart Grid, vol. 5, pp. 121-129, 2014.

[13] P. Mancarella and G. Chicco, "Real-time demand response from energy shifting in distributed multigeneration," IEEE Transactions on Smart Grid, vol. 4, pp. 1928-1938, 2013.

[14] J. Li, Z. Wu, S. Zhou, H. Fu, and X.-P. Zhang, "Aggregator service for PV and battery energy storage systems of residential building," CSEE Journal of Power and Energy Systems, vol. 1, pp. 3-11, 2015.

[15] K. Stenner, E. R. Frederiks, E. V. Hobman, and S. Cook, "Willingness to participate in direct load control: The role of consumer distrust," Applied energy, vol. 189, pp. 76-88, 2017.

[16] G. Ye, G. Li, D. Wu, X. Chen, and Y. Zhou, "Towards Cost Minimization with Renewable Energy Sharing in Cooperative Residential Communities," IEEE Access, 2017.

[17] B. Celik, R. Roche, D. Bouquain, and A. Miraoui, "Coordinated neighborhood energy sharing using game theory and multi-agent systems," in PowerTech, 2017 IEEE Manchester, 2017, pp. 1-6.

[18] T. Liu, X. Tan, B. Sun, Y. Wu, X. Guan, and D. H. Tsang, "Energy management of cooperative microgrids with p2p energy sharing in distribution networks," in Smart Grid Communications (SmartGridComm), 2015 IEEE International Conference on, 2015, pp. 410-415.

[19] S. Bahrami, M. H. Amini, M. Shafie-Khah, and J. P. Catalao, "A decentralized renewable generation management and demand response in power distribution networks," IEEE Transactions on Sustainable Energy, vol. 9, pp. 1783-1797, 2018.

[20] D. Ilic, P. G. Da Silva, S. Karnouskos, and M. Griesemer, "An energy market for trading electricity in smart grid neighbourhoods," in Digital Ecosystems Technologies (DEST), 2012 6th IEEE International Conference on, 2012, pp. 1-6.

[21] A. Sheikhi, M. Rayati, S. Bahrami, and A. M. Ranjbar, "Integrated demand side management game in smart energy hubs," IEEE Transactions on Smart Grid, vol. 6, pp. 675-683, 2015.

[22] A. Sheikhi, S. Bahrami, and A. M. Ranjbar, "An autonomous demand response program for electricity and natural gas networks in smart energy hubs," Energy, vol. 89, pp. 490-499, 2015.

[23] A. Sheikhi, M. Rayati, S. Bahrami, and A. M. Ranjbar, "Demand side management in a group of Smart Energy Hubs as price anticipators; The game theoretical approach," in 2015 IEEE Power \& Energy Society Innovative Smart Grid Technologies Conference (ISGT), 2015, pp. 1-5.

[24] M. H. Albadi and E. F. El-Saadany, "Demand response in electricity markets: An overview," in Power Engineering Society General Meeting, 2007. IEEE, 2007, pp. 1-5.

[25] T. Peng and K. Tomsovic, "Congestion influence on bidding strategies in an electricity market," IEEE Transactions on Power Systems, vol. 18, pp. 1054-1061, 2003.

[26] W. Shi, N. Li, C.-C. Chu, and R. Gadh, "Real-time energy management in microgrids," IEEE Transactions on Smart Grid, vol. 8, pp. 228-238, 2017.

[27] S. Zhou, Z. Wu, J. Li, and X.-p. Zhang, "Real-time energy control approach for smart home energy management system," Electric Power Components and Systems, vol. 42, pp. 315-326, 2014.

[28] H. Fang, D. Wu, and T. Yang, "Cooperative management of a lithium-ion battery energy storage network: A distributed MPC approach," in Decision and Control (CDC), 2016 IEEE 55th Conference on, 2016, pp. 42264232.

[29] K. Hashikura, H. Koura, K. Umeda, and A. Kojima, "An explicit design method of robust periodic MPC with application to charge-level control of photovoltaic battery," in Decision and Control (CDC), 2015 IEEE 54th Annual Conference on, 2015, pp. 7578-7585.

[30] T. Zhang, Y. Zhang, H. Lei, B. Guo, and Y. Zha, "Optimal microgrid operation based on model predictive control framework," in Control, Automation and Robotics (ICCAR), 2017 3rd International Conference on, 2017, pp. 575-581.

\section{APPENDIX}

\section{A. Domestic Bills Comparison under Different PV Penetration}

Table 1 Bill Comparison at 20\% PV Penetration Level

\begin{tabular}{|c|c|c|c|}
\hline & $\begin{array}{c}\text { Bill(Wholes } \\
\text { ale) }\end{array}$ & $\begin{array}{c}\text { After(Energy } \\
\text { Pool) }\end{array}$ & Saving(\%) \\
\hline Home1 & 58.62 & 20.55 & 64.94 \\
\hline Home2 & -13.21 & -55.12 & -317.11 \\
\hline Home3 & 13.14 & -17.70 & 234.76 \\
\hline Home4 & 23.50 & -11.25 & 147.87 \\
\hline Home5 & -21.80 & -65.26 & -199.35 \\
\hline Home6 & -40.16 & -89.57 & -123.04 \\
\hline Home7 & -27.97 & -73.11 & -161.36 \\
\hline Home8 & -32.50 & -79.83 & -145.65 \\
\hline Home9 & -16.57 & -59.52 & -259.20 \\
\hline Home10 & 10.13 & -27.47 & 371.11 \\
\hline Home11 & 29.48 & 27.09 & 8.10 \\
\hline Home12 & 125.91 & 125.12 & 0.63 \\
\hline Home13 & 24.22 & 23.03 & 4.93 \\
\hline
\end{tabular}




\begin{tabular}{|c|c|c|c|}
\hline Home14 & 52.61 & 49.10 & 6.66 \\
\hline Home15 & 61.47 & 57.50 & 6.46 \\
\hline Home16 & 38.35 & 34.28 & 10.63 \\
\hline Home17 & 38.23 & 34.76 & 9.09 \\
\hline Home18 & 91.98 & 89.56 & 2.63 \\
\hline Home19 & 56.10 & 53.27 & 5.05 \\
\hline Home20 & 39.18 & 34.84 & 11.08 \\
\hline Home21 & 46.61 & 43.53 & 6.60 \\
\hline Home22 & 48.19 & 45.67 & 5.21 \\
\hline Home23 & 63.42 & 58.97 & 7.02 \\
\hline Home24 & 76.11 & 72.47 & 4.79 \\
\hline Home25 & 75.76 & 71.17 & 6.06 \\
\hline Home26 & 44.33 & 42.93 & 3.16 \\
\hline Home27 & 39.70 & 37.79 & 4.80 \\
\hline Home28 & 27.62 & 25.18 & 8.83 \\
\hline Home29 & 62.39 & 57.53 & 7.79 \\
\hline Home30 & 44.34 & 41.09 & 7.34 \\
\hline Home31 & 53.11 & 49.22 & 7.33 \\
\hline Home32 & 91.02 & 85.96 & 5.56 \\
\hline Home33 & 319.70 & 313.23 & 2.02 \\
\hline Home34 & 84.12 & 78.47 & 6.72 \\
\hline Home35 & 290.38 & 300.39 & -3.45 \\
\hline Home36 & 45.94 & 42.30 & 7.94 \\
\hline Home37 & 28.54 & 27.82 & 2.52 \\
\hline Home38 & 54.63 & 50.23 & 8.07 \\
\hline Home39 & 42.34 & 40.26 & 4.91 \\
\hline Home40 & 57.35 & 54.98 & 4.12 \\
\hline Home41 & 41.48 & 37.93 & 8.58 \\
\hline Home42 & 39.53 & 37.21 & 5.86 \\
\hline Home43 & 38.84 & 35.35 & 8.99 \\
\hline Home44 & 29.04 & 26.08 & 10.19 \\
\hline Home45 & 35.26 & 32.70 & 7.24 \\
\hline Home46 & 39.20 & 37.37 & 4.66 \\
\hline Home47 & 59.61 & 55.15 & 7.49 \\
\hline Home48 & 35.77 & 32.74 & 8.49 \\
\hline Home49 & 101.05 & 94.43 & 6.55 \\
\hline Home50 & 76.47 & 72.06 & 5.77 \\
\hline
\end{tabular}

Table 2 Bill Comparison at 50\% PV Penetration Level

\begin{tabular}{|c|c|c|c|}
\hline & $\begin{array}{c}\text { Bill(Wholes } \\
\text { ale) }\end{array}$ & $\begin{array}{c}\text { After(Energy } \\
\text { Pool) }\end{array}$ & Saving(\%) \\
\hline Home1 & 58.62 & 54.94 & 6.28 \\
\hline Home2 & -13.21 & -21.55 & -63.06 \\
\hline Home3 & 13.14 & 9.29 & 29.27 \\
\hline Home4 & 23.50 & 18.08 & 23.09 \\
\hline Home5 & -21.80 & -29.84 & -36.86 \\
\hline Home6 & -40.16 & -51.33 & -27.82 \\
\hline
\end{tabular}

\begin{tabular}{|c|c|c|c|}
\hline Home7 & -27.97 & -37.06 & -32.46 \\
\hline Home8 & -32.50 & -42.46 & -30.67 \\
\hline Home9 & -16.57 & -24.04 & -45.10 \\
\hline Home10 & 10.13 & 4.01 & 60.41 \\
\hline Home11 & -30.51 & -40.55 & -32.91 \\
\hline Home12 & 58.62 & 54.94 & 6.28 \\
\hline Home13 & -31.10 & -43.29 & -39.23 \\
\hline Home14 & -14.53 & -21.20 & -45.89 \\
\hline Home15 & -6.48 & -12.86 & -98.49 \\
\hline Home16 & -28.09 & -36.44 & -29.71 \\
\hline Home17 & -26.15 & -34.76 & -32.96 \\
\hline Home18 & 22.13 & 17.33 & 21.65 \\
\hline Home19 & -9.26 & -16.50 & -78.15 \\
\hline Home20 & -26.15 & -35.13 & -34.33 \\
\hline Home21 & -19.66 & -26.85 & -36.63 \\
\hline Home22 & -16.64 & -23.32 & -40.19 \\
\hline Home23 & -6.23 & -12.24 & -96.29 \\
\hline Home24 & 7.44 & 1.86 & 75.01 \\
\hline Home25 & 4.14 & -1.15 & 127.80 \\
\hline Home26 & 44.33 & 38.54 & 13.06 \\
\hline Home27 & 39.70 & 32.53 & 18.04 \\
\hline Home28 & 27.62 & 21.13 & 23.50 \\
\hline Home29 & 62.39 & 49.30 & 20.98 \\
\hline Home30 & 44.34 & 35.30 & 20.38 \\
\hline Home31 & 53.11 & 42.25 & 20.46 \\
\hline Home32 & 91.02 & 75.66 & 16.87 \\
\hline Home33 & 319.70 & 291.99 & 8.67 \\
\hline Home34 & 84.12 & 67.40 & 19.88 \\
\hline Home35 & 290.38 & 298.09 & -2.65 \\
\hline Home36 & 45.94 & 37.29 & 18.84 \\
\hline Home37 & 28.54 & 25.58 & 10.38 \\
\hline Home38 & 54.63 & 43.39 & 20.59 \\
\hline Home39 & 42.34 & 35.90 & 15.20 \\
\hline Home40 & 57.35 & 46.58 & 18.78 \\
\hline Home41 & 41.48 & 31.97 & 22.94 \\
\hline Home42 & 39.53 & 32.79 & 17.05 \\
\hline Home43 & 38.84 & 30.36 & 21.83 \\
\hline Home44 & 29.04 & 22.16 & 23.69 \\
\hline Home45 & 35.26 & 28.29 & 19.75 \\
\hline Home46 & 39.20 & 34.10 & 13.02 \\
\hline Home47 & 59.61 & 47.29 & 20.67 \\
\hline Home48 & 35.77 & 28.66 & 19.89 \\
\hline Home49 & 101.05 & 81.85 & 19.00 \\
\hline Home50 & 76.47 & 63.33 & 17.19 \\
\hline & & & \\
\hline
\end{tabular}

Table 3 Bill Comparison at 100\% PV Penetration Level \begin{tabular}{|l|l|l|}
\hline Bill(Wholesal & After(Energy & Saving(\%) \\
\hline
\end{tabular} 


\begin{tabular}{|c|c|c|c|}
\hline & e) & Pool) & \\
\hline Home1 & 58.6172 & 58.6142 & -0.01 \\
\hline Home2 & -13.2149 & -15.9824 & 20.94 \\
\hline Home3 & 13.1367 & 12.0901 & -7.97 \\
\hline Home4 & 23.5046 & 21.3441 & -9.19 \\
\hline Home5 & -21.8012 & -24.0673 & 10.39 \\
\hline Home6 & -40.16 & -43.3865 & 8.03 \\
\hline Home7 & -27.9749 & -31.0492 & 10.99 \\
\hline Home8 & -32.497 & -35.1423 & 8.14 \\
\hline Home9 & -16.5699 & -18.1403 & 9.48 \\
\hline Home10 & 10.1328 & 7.226 & -28.69 \\
\hline Home11 & -30.5062 & -33.2276 & 8.92 \\
\hline Home12 & 58.6172 & 58.6142 & -0.01 \\
\hline Home13 & -31.0953 & -35.1639 & 13.08 \\
\hline Home14 & -14.5342 & -15.6629 & 7.77 \\
\hline Home15 & -6.4802 & -7.8854 & 21.68 \\
\hline Home16 & -28.0903 & -30.5717 & 8.83 \\
\hline Home17 & -26.1463 & -28.2114 & 7.90 \\
\hline Home18 & 22.1263 & 18.9717 & -14.26 \\
\hline Home19 & -9.2636 & -12.0295 & 29.86 \\
\hline Home20 & -26.154 & -28.6724 & 9.63 \\
\hline Home 21 & -19.6552 & -21.44 & 9.08 \\
\hline Home22 & -16.6379 & -17.2251 & 3.53 \\
\hline Home23 & -6.2339 & -7.5492 & 21.10 \\
\hline Home24 & 7.4374 & 5.8893 & -20.82 \\
\hline Home 25 & 4.1393 & 2.4107 & -41.76 \\
\hline Home26 & -18.9094 & -20.1329 & 6.47 \\
\hline Home27 & -22.3855 & -25.122 & 12.22 \\
\hline Home28 & -33.2883 & -36.0573 & 8.32 \\
\hline Home29 & -8.1653 & -9.6796 & 18.55 \\
\hline Home30 & -21.6185 & -23.2133 & 7.38 \\
\hline Home31 & -15.9521 & -17.2005 & 7.83 \\
\hline Home 32 & 15.0997 & 14.1751 & -6.12 \\
\hline Home33 & 225.5318 & 219.643 & -2.61 \\
\hline Home34 & 9.3283 & 6.0599 & -35.04 \\
\hline Home35 & 233.5547 & 238.5374 & 2.13 \\
\hline Home36 & -19.4299 & -21.1616 & 8.91 \\
\hline Home 37 & -28.8385 & -31.5414 & 9.37 \\
\hline Home38 & -14.2569 & -15.7385 & 10.39 \\
\hline Home39 & -20.893 & -22.0762 & 5.66 \\
\hline Home40 & -10.5039 & -14.7344 & 40.28 \\
\hline Home41 & -24.1773 & -26.5253 & 9.71 \\
\hline Home42 & -23.7911 & -25.5229 & 7.28 \\
\hline Home43 & -25.2422 & -26.9625 & 6.82 \\
\hline Home44 & -32.4472 & -35.0024 & 7.87 \\
\hline Home 45 & -26.2215 & -29.282 & 11.67 \\
\hline
\end{tabular}

\begin{tabular}{|c|c|c|c|}
\hline Home46 & -21.3287 & -23.2602 & 9.06 \\
\hline Home47 & -8.0637 & -11.4207 & 41.63 \\
\hline Home48 & -26.3194 & -28.4529 & 8.11 \\
\hline Home49 & 2123.75 & 1976.79 & 6.92 \\
\hline Home50 & 340.78 & 181.83 & 46.64 \\
\hline
\end{tabular}

\section{B. Customer Bidding Information for UDDSR}

Table 4 Customer Bid Information at Serious Imbalance Level

\begin{tabular}{|c|c|c|c|c|}
\hline & $\begin{array}{c}\text { Start } \\
\text { Time }\end{array}$ & $\begin{array}{c}\text { End } \\
\text { Time }\end{array}$ & Duration & $\begin{array}{l}\text { Rating } \\
\text { Power }\end{array}$ \\
\hline Home1 & 2 & 9 & 3 & 1 \\
\hline Home2 & 2 & 12 & 7 & 1 \\
\hline Home3 & 1 & 5 & 3 & 1 \\
\hline Home4 & 3 & 10 & 5 & 1 \\
\hline Home5 & 1 & 12 & 10 & 1 \\
\hline Home6 & 3 & 9 & 3 & 1 \\
\hline Home7 & 2 & 10 & 8 & 1 \\
\hline Home8 & 2 & 7 & 3 & 1 \\
\hline Home9 & 4 & 10 & 5 & 1 \\
\hline Home10 & 2 & 10 & 6 & 1 \\
\hline Home11 & 2 & 10 & 3 & 1 \\
\hline Home12 & 3 & 12 & 5 & 1 \\
\hline Home13 & 5 & 10 & 4 & 1 \\
\hline Home14 & 1 & 12 & 5 & 1 \\
\hline Home15 & 2 & 9 & 3 & 1 \\
\hline Home16 & 3 & 10 & 7 & 1 \\
\hline Home17 & 3 & 12 & 6 & 1 \\
\hline Home18 & 1 & 12 & 8 & 1 \\
\hline Home19 & 1 & 6 & 3 & 1 \\
\hline Home 20 & 3 & 10 & 4 & 1 \\
\hline Home 21 & 2 & 12 & 6 & 1 \\
\hline Home 22 & 2 & 10 & 6 & 1 \\
\hline Home23 & 6 & 12 & 5 & 1 \\
\hline Home24 & 2 & 12 & 7 & 1 \\
\hline Home25 & 5 & 10 & 3 & 1 \\
\hline Home26 & 7 & 12 & 3 & 1 \\
\hline Home27 & 2 & 10 & 6 & 1 \\
\hline Home28 & 1 & 9 & 5 & 1 \\
\hline Home29 & 3 & 11 & 8 & 1 \\
\hline Home 30 & 2 & 6 & 4 & 1 \\
\hline Home31 & 2 & 6 & 3 & 1 \\
\hline Home 32 & 1 & 12 & 4 & 1 \\
\hline Home33 & 2 & 12 & 10 & 1 \\
\hline Home34 & 3 & 12 & 8 & 1 \\
\hline Home35 & 2 & 11 & 4 & 1 \\
\hline Home36 & 5 & 12 & 5 & 1 \\
\hline
\end{tabular}




\begin{tabular}{|c|c|c|c|c|}
\hline Home37 & 1 & 12 & 7 & 1 \\
\hline Home38 & 1 & 10 & 5 & 1 \\
\hline Home39 & 5 & 12 & 5 & 1 \\
\hline Home40 & 3 & 10 & 5 & 1 \\
\hline Home41 & 1 & 9 & 6 & 1 \\
\hline Home42 & 4 & 10 & 4 & 1 \\
\hline Home43 & 7 & 12 & 2 & 1 \\
\hline Home44 & 6 & 12 & 3 & 1 \\
\hline Home45 & 1 & 9 & 3 & 1 \\
\hline Home46 & 1 & 8 & 3 & 1 \\
\hline Home47 & 3 & 12 & 5 & 1 \\
\hline Home48 & 2 & 10 & 6 & 1 \\
\hline Home49 & 3 & 11 & 5 & 1 \\
\hline Home50 & 2 & 12 & 7 & 1 \\
\hline
\end{tabular}

Table 5 Customer Bid Information at Relatively Balance

\begin{tabular}{|c|c|c|c|c|}
\hline & $\begin{array}{c}\text { Start } \\
\text { Time }\end{array}$ & $\begin{array}{c}\text { End } \\
\text { Time }\end{array}$ & Duration & $\begin{array}{c}\text { Rating } \\
\text { Power }\end{array}$ \\
\hline Home1 & 2 & 9 & 3 & 1 \\
\hline Home2 & 1 & 12 & 7 & 1 \\
\hline Home3 & 1 & 5 & 3 & 1 \\
\hline Home4 & 1 & 10 & 5 & 1 \\
\hline Home5 & 1 & 12 & 10 & 1 \\
\hline Home6 & 1 & 9 & 3 & 1 \\
\hline Home7 & 1 & 10 & 8 & 1 \\
\hline Home8 & 1 & 7 & 3 & 1 \\
\hline Home9 & 4 & 10 & 5 & 1 \\
\hline Home10 & 1 & 10 & 6 & 1 \\
\hline Home11 & 2 & 10 & 3 & 1 \\
\hline Home12 & 3 & 12 & 5 & 1 \\
\hline Home13 & 1 & 10 & 4 & 1 \\
\hline Home14 & 1 & 12 & 5 & 1 \\
\hline Home15 & 2 & 9 & 3 & 1 \\
\hline Home16 & 3 & 10 & 7 & 1 \\
\hline Home17 & 3 & 12 & 6 & 1 \\
\hline Home18 & 1 & 12 & 8 & 1 \\
\hline Home19 & 1 & 6 & 3 & 1 \\
\hline Home20 & 1 & 10 & 4 & 1 \\
\hline Home21 & 1 & 12 & 6 & 1 \\
\hline Home22 & 2 & 10 & 6 & 1 \\
\hline Home23 & 6 & 12 & 5 & 1 \\
\hline Home24 & 2 & 12 & 7 & 1 \\
\hline Home25 & 5 & 10 & 3 & 1 \\
\hline Home26 & 7 & 12 & 3 & 1 \\
\hline Home27 & 2 & 10 & 6 & 1 \\
\hline
\end{tabular}

\begin{tabular}{|c|c|c|c|c|}
\hline Home28 & 1 & 9 & 5 & 1 \\
\hline Home29 & 3 & 11 & 8 & 1 \\
\hline Home30 & 2 & 6 & 4 & 1 \\
\hline Home31 & 2 & 6 & 3 & 1 \\
\hline Home32 & 1 & 12 & 4 & 1 \\
\hline Home33 & 2 & 12 & 10 & 1 \\
\hline Home34 & 3 & 12 & 8 & 1 \\
\hline Home35 & 2 & 11 & 4 & 1 \\
\hline Home36 & 5 & 12 & 5 & 1 \\
\hline Home37 & 1 & 12 & 7 & 1 \\
\hline Home38 & 1 & 10 & 5 & 1 \\
\hline Home39 & 5 & 12 & 5 & 1 \\
\hline Home40 & 3 & 10 & 5 & 1 \\
\hline Home41 & 1 & 9 & 6 & 1 \\
\hline Home42 & 4 & 10 & 4 & 1 \\
\hline Home43 & 7 & 12 & 2 & 1 \\
\hline Home44 & 6 & 12 & 3 & 1 \\
\hline Home45 & 1 & 9 & 3 & 1 \\
\hline Home46 & 1 & 8 & 3 & 1 \\
\hline Home47 & 3 & 12 & 5 & 1 \\
\hline Home48 & 2 & 10 & 6 & 1 \\
\hline Home49 & 3 & 11 & 5 & 1 \\
\hline Home50 & 2 & 12 & 7 & 1 \\
\hline
\end{tabular}

